19 Revue d'histoire du XIXe siècle

Société d'histoire de la révolution de 1848 et des

révolutions du XIXe siècle

$20 / 21 \mid 2000$

Varia

\title{
Colloque : Terminée la Révolution... Programme
}

Quatrième colloque européen de Calais, 26 et 27 janvier 2001

\section{(2) OpenEdition \\ Journals}

Édition électronique

URL : http://journals.openedition.org/rh19/240

DOI : $10.4000 /$ rh 19.240

ISSN : 1777-5329

Éditeur

La Société de 1848

Édition imprimée

Date de publication : 1 juin 2000

ISSN : 1265-1354

Référence électronique

«Colloque : Terminée la Révolution... Programme », Revue d'histoire du XIXe siècle [En ligne], 20/21 |

2000, mis en ligne le 04 septembre 2008, consulté le 15 septembre 2020. URL : http://

journals.openedition.org/rh19/240

Ce document a été généré automatiquement le 15 septembre 2020.

Tous droits réservés 


\section{Colloque : Terminée la Révolution... Programme}

Quatrième colloque européen de Calais, 26 et 27 janvier 2001

1 Sous la présidence d'honneur du professeur Jean-Paul BERTAUD (Université Paris IPanthéon Sorbonne)

À l'initiative du comité local du bicentenaire de la Révolution française et avec le soutien de la Ville de Calais, de la Chambre de commerce et d'industrie de Calais, des Amis du Vieux Calais, de l'Institut d'Histoire de la Révolution française (Université Paris I), du CHREN-O (Université Lille III), de l'Université d'Artois, de l'Université de Rouen, de l'Université du Littoral, de la Société des études robespierristes.

Responsable du projet : Michel BIARD

Comité d'organisation: Christine LE BOZEC ; Jean-Pierre JESSENNE ; Hervé LEUWERS; Stéphane CURVEILLER ; Michel BIARD.

Comité scientifique : Bronislaw BACZKO ; Jean-Paul BERTAUD ; Jean-Clément MARTIN ; Jean-Luc MAYAUD; Claude MAZAURIC; Michel PERTUÉ; Michel VOVELLE; Serge WOLIKOW.

Députés aux États généraux persuadés de regagner bien vite leur province, Monarchiens soucieux d'imposer leur vision de l'État, Jacobins du printemps 1791 avides de " surmonter tous les obstacles et terminer la Révolution ", Brissotins en butte à l'hostilité populaire parisienne, Robespierristes au printemps de l'an II, Thermidoriens... tous ont été confrontés, dans leur diversité, à la question qui hante les acteurs de chaque mouvement révolutionnaire: quand et comment terminer la Révolution? Avec quels héritages, sur la base de quelles structures étatiques, avec quelle conception de la participation des citoyens au pouvoir, avec quels choix économiques et sociaux, marquer l'achèvement de la Révolution? Jouant des continuités tout en validant force ruptures, le Consulat puis l'Empire ont semblé être par excellence le moment de la transition. Pour autant, le retour de Louis XVIII est mis en scène comme la fin d'une trop longue parenthèse qui rejette Révolution, Consulat et Empire dans une même solution de continuité qui doit être oubliée et qui n'est pas parvenue à mettre à mort une monarchie pluriséculaire. Au temps de l'opprobre succède néanmoins celui des révolutions, $1830,1848,1871$, avec un souvenir transmis 
de génération en génération qui fait de la Révolution française un élément fondamental de l'imaginaire républicain.

Cet imaginaire républicain, avec son panthéon choisi, avec ses références culturelles et politiques, a été au cœur du bicentenaire organisé autour de 1989, en cette fin du XXe siècle où la révolution peut presque apparaître, à l'instar des accidents, comme un événement qui n'arrive qu'aux autres. Les mouvements révolutionnaires ne sont-ils pas avant tout aujourd'hui le fait des pays que l'on regroupait volontiers hier sous la symbolique appellation de "tiers-monde " ? À moins qu'il ne faille s'interroger sur le sens du terme " révolution " lui-même...

Après plus d'une décennie d'existence et d'activités multiformes, le Comité calaisien pour la célébration du bicentenaire de la Révolution française a choisi d'ouvrir le nouveau millénaire en réorientant sa réflexion vers la conquête et l'exercice de la citoyenneté. En cet instant qui lie étroitement disparition et renaissance, ses membres ont voulu organiser une rencontre qui, réunissant chercheurs et citoyens, permette de faire le point sur la chronique d'une mort annoncée... peut-être avec trop de précipitation?

\section{PROGRAMME}

Vendredi 26 janvier (matin) : REVOLUTION NIEE, REVOLUTION ASSUMEE

Ouverture du colloque (9h30)

Perspectives scientifiques de la rencontre (Michel BIARD)

Présidence : Bronislaw BACZKO (Université de Genève)

Jean-Pierre JESSENNE (Université de Rouen), Passé-présent, Révolution : équivoques et enjeux de la reconstruction du temps (1789-1848).

Philippe BOURDIN (Université de Clermont-Ferrand), Entre deux siècles, l'impossible bilan : la Révolution au crible de la satire littéraire.

Jacques-Olivier BOUDON (Université de Rouen), 1814-1815 : entre Contre-Révolution et recharge révolutionnaire.

Jean-Claude CARON (Université de Clermont-Ferrand), Inscrire la Révolution dans l'Histoire: les Trois Glorieuses, coda, appendice ou palimpseste de la Grande Révolution?

Vendredi 26 janvier (après-midi) : 1799-1814 : le Consulat et l'Empire, un achèvement ?

\section{1 / Grandeur, pouvoirs, légitimité}

Présidence : Michel PERTUÉ (université d'Orléans)

Rapporteur : Annie CRÉPIN (Université d'Artois)

Jean-Paul BERTAUD (Université Paris I-IHRF), Gloire militaire et vertus civiques.

Bernard GAINOT (Université Paris I-IHRF), Le pouvoir législatif, une fiction?

Josiane BOURGUET-ROUVEYRE (Université Paris I), La citoyenneté à l'épreuve du conformisme et de l'uniformité sous le Consulat et l'Empire.

Nathalie PETITEAU (Université d'Avignon), Les refus de l'Empire : de l'hostilité ouverte aux oppositions diffuses

\section{2 / Le tri des héritages}

Présidence : Christine LE BOZEC (Université de Rouen)

Rapporteur : Michel BIARD (Université Paris I-IHRF)

Michel PERTUÉ (Université d'Orléans), Le modèle administratif français.

Hervé LEUWERS (Université de Lille III - CHREN-O), Hommes de loi après la Révolution. 
Entre héritage revendiqué et renouveau assumé.

Pierre-Yves BEAUREPAIRE (Université d'Artois), Sociabilité et culture : neutralisation, instrumentalisation ou recomposition?

Annie JOURDAN (Université d'Amsterdam), Les artistes et le pouvoir de la Révolution à l'Empire.

Samedi 27 janvier (matin) : QUE RESTE-T-IL DE LA REVOLUTION FRANÇAISE ? (Ouverture des travaux à $9 \mathrm{~h})$

Présidence : Serge WOLIKOW (Université de Dijon)

Claude MAZAURIC (Université de Rouen), En finir avec la Révolution française ou finir la Révolution française ? Le premier XIXe siècle français à l'épreuve du modèle.

Louis HINCKER (CNRS), Expériences populaires de la prise d'arme révolutionnaire au XIXe siècle (légitimité et illégitimité du citoyen-combattant à Paris durant la Seconde République)

Philippe MINARD (Université Lille III), Un libéralisme mitigé ? État et économie après la Révolution.

Présidence : Claude MAZAURIC (Université de Rouen)

Jean-Clément MARTIN (Université Paris I-IHRF), Jeu symbolique ou exploitation politique, la Révolution entretenue par la Contre-Révolution.

Bruno BÉTHOUART (Université du Littoral), Les Chrétiens et la Révolution française : un enjeu majeur pour la France contemporaine.

Serge WOLIKOW (Université de Dijon), Les références à la Révolution française pour la Gauche et le mouvement ouvrier en France au XX $\mathrm{XX}^{\mathrm{e}}$ siècle.

Samedi 27 janvier (après-midi): L'IDEE DE REVOLUTION A L'AUBE DU XXIe SIECLE. Table ronde et débat public :

Coordination: Jean-Luc MAYAUD (Université Lyon 2), avec la participation de Bruna CONSARELLI (Université Rome III) ; Bronislaw BACZKO (Université de Genève) ; JeanPierre JESSENNE (Université de Rouen); Jean-Clément MARTIN (Université Paris IIHRF); Claude MAZAURIC (Université de Rouen).

Pour tout contact:

Michel BIARD, 88, rue du Temple, 62100 Calais

Tél : 03.21.34.30.85

Courriel : Michel.Biard@netinfo.fr 